\title{
Research on the Mechanism of the Effect of Employment Model on Employees' Innovation Behavior: Proposal of Conceptual Model
}

\author{
Guojing Xie*, Shao Fang \\ School of Economics and Management, Xidian University, Xi'an, China \\ Email: $793106917 @ q q . c o m$
}

How to cite this paper: Xie, G. J., \& Fang, S. (2020). Research on the Mechanism of the Effect of Employment Model on Employees' Innovation Behavior: Proposal of Conceptual Model. Open Journal of Business and Management, 8, 1375-1403.

https://doi.org/10.4236/ojbm.2020.84088

Received: May 9, 2020

Accepted: June 13, 2020

Published: June 16, 2020

Copyright () 2020 by author(s) and Scientific Research Publishing Inc. This work is licensed under the Creative Commons Attribution International License (CC BY 4.0).

http://creativecommons.org/licenses/by/4.0/

\begin{abstract}
This article focuses on two employment modes of fixed-term and non-fixed-term labor contracts. Based on the theory of social exchange, social identification and work-stress, this paper proposes a conceptual model of the mechanism of employment mode's impact on employees' innovative behavior. The article systematically expounds the direct impact of the employment model on employee innovation behavior through work safety and organizational identity, and the indirect impact of the employment model on the fulfillment of corporate psychological contracts and employee responses. This article explores the mechanism of the employment model's impact on employees' innovative behavior, and is committed to opening the "black box" of the relationship between the employment model and employee's innovative behavior.
\end{abstract}

\section{Keywords}

Employment Model, Employee Innovation Behavior, Psychological Contract, Organizational Identity, Work Safety

\section{Introduction}

With the development of global economic integration, the external environment of China's labor market is gradually developing towards dynamic and unpredictable. Changes in the labor market have changed the power relationship between capital and labor, and increased the vulnerability of workers and unstable employment. A sudden outbreak in early 2020 caused a huge impact on many industries in a short period of time. The first thing to do was the catering industry. Haidilao suspended its operations. Hundreds of Starbucks stores were 
closed. The same is true of industries such as film and television and transportation. In such a severe environment, enterprises cannot resume work, and many employees have been "resigned". After the epidemic, employment has become their main demand. However, behind every major event there is also a new birth. Along with the epidemic, some logistics companies and take-out platforms are still operating normally, and even a "zero-touch" retail method such as a 10-foot functional breakfast cabinet has appeared. Hema even accepts other catering companies through "renting employees". Some of the employees have settled in the store. This flexible way of employment is more a form of cooperation between the enterprise and employees. Existing theories and studies have recognized the important role of employment patterns between companies and employees in employee behavior, but failed to establish an effective connection between the two, making research on how employment patterns affect employee innovation behavior, there is still controversy. Why do companies with different employment modes have different anti-risk capabilities in the same external environment? How can companies improve their innovative behaviors through cooperation with employees in a win-win manner and realize the transformation of employment advantages into competitive advantages? This is a research topic that requires continuous attention.

The emergence of new employment methods has a close relationship with the enterprise's active reform and innovation. In the current Chinese social environment, economic growth is inseparable from innovation. Under the guidance of the innovation-driven development strategy, the development of Chinese enterprises is changing from followers in the past to current peers and even future leaders. The performance of companies from Ant Financial, Huawei Technologies, Xiaomi Technology and others in the global enterprise list is evident. In this epidemic, Wanda Group announced that it would exempt the merchants of Wanda Plaza from one month's rent. Wanda's decision reflects the responsibility and responsibility of a large enterprise. However, economic recovery and development innovation are not enough to rely on the strength of the enterprise. It is also necessary to fully tap the strength and creativity of each individual employee in the enterprise. Individual employees, as the "single cell" of an organization, are the specific implementers of organizational innovation. Individual innovation is the cornerstone of corporate innovation, change, and competition. But not every employee will contribute his or her innovative behavior to the organization unconditionally. In fact, the innovation of employees in the organization requires enough courage to overcome the risks. Therefore, how to minimize the risk of employee innovation, stimulate employees' innovative thinking and promote their transformation into innovative behaviors has become a key step in organizational innovation. In order to achieve this goal, it also needs the continuous support of the measures and psychological mechanisms established by the organization under different employment modes to stimulate employees' innovative behavior. 
Throughout the comparison of the employment patterns of enterprises in other countries and the employment patterns of Chinese enterprises, there are also different conclusions. The developed labor market in the United States determines the temporary employment model adopted by American companies. This employment model broadens the selection of talents and strengthens the competition mechanism. To a certain extent, it will also stimulate the innovative behavior of employees, but it is also inevitably, the impact of the external dynamic environment has caused a huge impact on the US economy, and employees are likely to be affected by unemployment. Japan's "lifetime employment system" is the core system of its human resource management. Under this system, due to the long-term cooperation between the organization and employees, employees can take the initiative to transform their "hidden factors" into internal "organizational factors", "Dominant factor", it can be said that the development of Japan after World War II benefited from the innovative behavior of employees, but too much emphasis on the stability of employment in the low-speed economic growth stage will also bring about the disadvantages of rigid management systems. At the same time, in the epidemic in China, the traditional permanent employment model showed its unparalleled advantages. A considerable number of employees in business establishments and state-owned enterprises were exempted from the unemployment crisis. Although the original long-term stable and almost risk-free employment guarantees gradually disappeared with the reform of the economic system in China, the traditional typical employment model still exists for a long time, and it occupies an important position in the employment choice of employees with its unique stability.

Previous studies have focused on the relationship between a single organizational characteristic and employees, but few studies have explored in depth how organizations and employees seek cooperation and mutual benefit in the face of the dynamic changes in the external environment of the labor market. As for the external characteristics of the organization, the employment model, as an objective existence, how to influence the internal psychological process of the individual and thus influence the innovation behavior of employees is very rare. In addition to external objective reasons, the perception between employees and the organization, such as organizational identity and job safety, is another important factor that affects individual creative behavior. In addition, the psychological contract is an important manifestation of the relationship between the organization and employees, and it is a psychologically unique and relatively stable agreement between the individual and the organization. With the intensification of competition and the rapid change of the operating environment, organizations need employees to have a strong initiative and flexibility to deal with the unknown and challenges in their work. Therefore, it is of great significance to explore the role of employment model in the relationship between psychological contract, organizational identity, etc. and employee innovation behavior. 
Next, this paper mainly introduces the research on the employment model and employee innovation behavior, the relationship between the employment model and employee innovation behavior, and the introduction of the model mechanism, including two intermediary mechanisms and one adjustment mechanism, and finally puts forward the model diagram and research conclusions of this article.

\section{Literature Review}

\subsection{Research on Employment Model}

The different employment models between enterprises and employees show different types of labor contracts, which to a certain extent represent the mutual responsibility of the two and the recognition of the value of employees by the organization. The current employment model is mainly divided into two categories, namely: permanent employment (standardized employment) and temporary employment (non-standardized employment). Permanent employment refers to employees working in the work place provided by the employer and full-time work under their supervision (De Cuyper et al., 2008). Generally speaking, the employment relationship has no clear end date and can be extended indefinitely; the definition of temporary employment is the most widely used in the world. The definition made by the Economic Cooperation Organization (OECD) "temporary employment consists of fixed-term contract employment, which is different from permanent employment and has a contract expiration period". In addition, Connelly and Gallagher (2004) pointed out that temporary employment also includes many categories, including labor agents, self-employment, fixed-term contract employees directly employed by employers, seasonal contract employees directly employed by employers, etc. The fixed-term employment model is the most widely used and most important temporary employment model. When De Graaf-Zijl (2012) studied the employment data in 2007, he found that $70 \%$ of Dutch employees start with fixed-term contract employees; while China's new "Labor Contract Law" legally protects the rights and interests of employees with fixed-term labor contracts At the same time, it also stipulates the relevant legal provisions for the conversion of fixed-term employees into non-fixed-term employees, in order to effectively protect the legitimate rights and interests of workers. There are large differences between these types of employment, and they should not be confused in the study. At present, many studies only point out that the research object is temporary workers, and there is no molecular class, or involve several different types of temporary workers at the same time. As proposed by LaMontagne et al. (2012), there is a clear difference between temporary and permanent employment, and the difference between various temporary employees is even greater than the former.

In the early research, scholars focused on whether there are differences in spe- 
cific behaviors between long-term employees and temporary employees, including organizational citizenship behavior and suggestions. However, the research conclusions are very different. Some studies have found that temporary employment has a negative impact on employee behavior. For example, Tak and Lim (2008) found that non-professional temporary employees have lower professional commitment and Occupational satisfaction, Gash studied statistical data from Spain and Germany that fixed-term contracts are not conducive to the organization of employee citizenship behavior (Gash et al., 2007). De Graaf-Zijl studied the Dutch social statistics report that fixed-term contracts have a negative impact on employees' work safety; some studies have found that temporary employment has a positive impact on employee behavior, For example, Van Dyne and Ang found that Singapore's fixed-term employees' organizational citizenship behavior is more positive; at the same time, some studies have found that temporary employment has no effect on employee behavior (Clinton et al., 2011). The sample data shows that there is no significant difference in the performance of roles between temporarily hired employees, such as fixed-term, labor agency, seasonal employment, and employees with no fixed-term. The reason for the inconsistency of existing research conclusions may be that, on the one hand, there is no specific distinction between different types of employment models, on the other hand, there is no focus on a specific research background and environment. Therefore, this article focuses on the fixed-term employment model in the Chinese context.

In addition, scholars also pay attention to the difference between fixed-term employees and long-term employees, but in the past, there was little conclusion about whether the relationship between variables based on long-term employees applies to fixed employees. Therefore, this paper conducts a comparative study, focusing on whether employees with no fixed term and fixed term respond to a certain dependent variable. The research sample includes two types of employees. The existing research conclusions are shown in Table 1 below.

In the mechanism of employment mode adjustment, most studies point out that there are large differences between the two types of employees in terms of perception of corporate responsibility fulfillment, and these differences will affect employees' work safety and organizational identity. Therefore, this article further explores employees' perception of the actual performance of corporate responsibility. The psychological contract focuses on the perception and fulfillment of the responsibilities of the company and employees (Rousseau, 1989), which can be used to systematically discuss the views of employees on their own and the responsibilities and obligations of the company. At the same time, there is still little research on the employment model and psychological contract, so this article will pay more attention to the difference between fixed-term and non-fixed-term employees in terms of psychological contract. In addition, most existing research on the impact of employee responses regards job safety as a 
Table 1. Summary of research on the moderating effect of fixed-term labor contracts.

\begin{tabular}{|c|c|c|c|c|c|}
\hline Dependent variable & Independent variable & $\begin{array}{c}\text { Moderating effect } \\
\text { (fixed-term employees) }\end{array}$ & Regulation mechanism analysis & Author & $\begin{array}{c}\text { Sample } \\
\text { characteristics }\end{array}$ \\
\hline $\begin{array}{l}\text { Breaking of corporate } \\
\text { psychological } \\
\text { contract }\end{array}$ & $\begin{array}{l}\text { Work pressure, } \\
\text { emotional career } \\
\text { commitment }\end{array}$ & $\begin{array}{l}\text { Weakened, the correlation } \\
\text { between the two is less }\end{array}$ & $\begin{array}{l}\text { Employees with no fixed deadline } \\
\text { invest more in the enterprise, so they } \\
\text { are more sensitive to external stimuli }\end{array}$ & Yeh et al. (2007) & Taiwan, China \\
\hline Employability & $\begin{array}{l}\text { Job Satisfaction } \\
\text { Organizational } \\
\text { emotional } \\
\text { commitment }\end{array}$ & $\begin{array}{l}\text { Weaken, the two are not } \\
\text { related } \\
\text { Enhanced, the correlation } \\
\text { coefficient is greater }\end{array}$ & $\begin{array}{l}\text { The fixed-term employees accepted } \\
\text { the unstable nature of their work to a } \\
\text { certain extent, and turned their } \\
\text { attention to the guarantee of } \\
\text { employability for their careers }\end{array}$ & $\begin{array}{l}\text { De Cuyper \& De } \\
\text { Witte (2009) }\end{array}$ & Belgium \\
\hline $\begin{array}{l}\text { Fair distribution, } \\
\text { procedures and } \\
\text { interaction }\end{array}$ & $\begin{array}{l}\text { Organizational } \\
\text { commitment }\end{array}$ & $\begin{array}{l}\text { Weaken, the correlation } \\
\text { coefficient is smaller }\end{array}$ & $\begin{array}{l}\text { The fixed-term employees are also } \\
\text { sensitive to the actual treatment of the } \\
\text { company, but do not think that the } \\
\text { company is responsible for their own } \\
\text { notification }\end{array}$ & Manville (2008) & France \\
\hline Work safety & $\begin{array}{l}\text { Job Satisfaction } \\
\text { Work involved } \\
\text { Working pressure }\end{array}$ & $\begin{array}{l}\text { Weaken, the correlation } \\
\text { coefficient is smaller }\end{array}$ & $\begin{array}{l}\text { A fixed period of time does not } \\
\text { consider the company to be } \\
\text { responsible for job security, so there } \\
\text { is no sense of betrayal }\end{array}$ & $\begin{array}{l}\text { Mauno et al. } \\
\quad(2005)\end{array}$ & Finland \\
\hline $\begin{array}{l}\text { Job requirements and } \\
\text { job control }\end{array}$ & Employee health & Weakened, less relevant & $\begin{array}{l}\text { Fixed-term employees have a lower } \\
\text { expectation of job security and thus } \\
\text { have a weaker impact; while job } \\
\text { demands are similar to job control } \\
\text { expectations }\end{array}$ & $\begin{array}{l}\text { Bernhard-Oettel, } \\
\text { Sverke, \& De Witte } \\
\text { (2005) }\end{array}$ & Switzerland \\
\hline
\end{tabular}

dependent variable and studies its interaction with employment patterns. However, many studies have confirmed that employees' work safety will be negatively affected by the fixed-term employment model. In addition, most of the current research only focuses on employees' direct response to the dependent variable, but does not pay attention to whether the individual's response to employee-organizational social exchange will be affected by the type of employment model. Therefore, this article also pays attention to the actual fulfillment of corporate psychological contracts, and the absolute value provided by employees to employees in the role of this research mechanism.

\subsection{Research on Employee Innovation Behavior}

In the increasingly fierce market economy environment, the innovative behavior of employees is an important factor for enterprises to continue innovation and progress. However, because employee innovation is neither a role behavior expected by employees nor a clear company vision formed by employees and organizations, innovation behavior is completely a role behavior freely determined by employees, which is not recognized by the organization reward system. In the past, researchers mostly defined individual innovation from the perspective of process. For example, Scott and Bruce (1994) pointed out that individual innovation of employees began with the problem and finally solved the solution. Af- 
ter the proposal is put forward, it is to continue to find corresponding evidence support for their innovative ideas to prove the feasibility of innovative ideas. Some scholars have studied innovation in three aspects: 1) innovation in the process; 2) product and performance innovation; 3) human-based innovation cognition. It can be seen that innovation tends to focus more on results (products or applications). Some scholars refer to people's innovative cognition as creativity, which consists of three parts: professional knowledge, creative thinking skills and motivation. Amabile's research identified six categories of management practices that affect creativity, namely challenge, freedom, resources, workgroup characteristics, supervision encouragement, and organizational support.

Janssen defines the definition and scope of individual innovation performance on the basis of Scott and Bruce, and summarizes innovation behavior. The scope of personal innovation performance includes the creation, development and realization of innovative ideas or thinking. In empirical testing, traditional role performance and innovation performance are two variables commonly used by researchers, and are mostly used to represent the dimension of job performance. Regression analysis shows that when fairness perception is used as an intermediate variable, the two dimensions of job performance and job performance show a significant " $U$ " relationship, in which the peak of innovation performance is higher. Janssen and Van Yperen (2004) found that the two dimensions of job performance are also affected to varying degrees by the quality of leadership-member exchange and goal orientation. Among them, the influence of leadership-member quality on the two dimensional variables of job performance is significant; while goal orientation negatively affects role performance. To achieve rapid development in a market economy full of uncertain competition and continuous development, it is not enough for an organization to rely on the existing social rules to operate. It requires every employee to do well in his own job while exceeding standard role behavior In order to promote the development of organizational change under innovation. There are many types of employees' innovation behaviors, and they can be divided into incremental innovation and radical innovation according to their breakthrough. Incremental innovation is relatively primitive, which means that employees revise or improve the existing business management ideas or methods. Radical innovation means that employees put forward their original ideas or models. According to the perspective of employee role function, it is divided into two dimensions: in-role innovation and out-role innovation. Role innovation is to introduce important new behaviors into pre-existing roles in the context of job changes and job changes. The way of working is different from that of the predecessor, which is considered a role innovation. In-role innovation behavior refers to the innovation behavior that only changes the procedure or process in the individual's job position or job role. Out-role innovation behavior refers to the innovation behavior outside the individual's work position and job role. Out-role innovation 
behavior occurs frequently in departments and organizations. In short, innovative behavior involves a variety of factors, such as innovation in job suggestions, innovation in job roles, and innovation in thinking. Therefore, the evaluation of innovative behavior should also include similar multiple factors. The factors that affect employees' innovative behavior include multiple levels, as shown in Table

2 .

\subsection{Research on the Relationship between Employment Mode and Employees' Innovative Behavior}

\subsubsection{Employment Mode and Off-Role Behavior}

1) Research on the reciprocity perspective of organization and employees

March and Simon (1958) proposed an incentive-contribution model, which explored the relationship between employee contributions to the organization and the incentives provided by the enterprise. One of the important models is an organization-centric mutual investment type employment model. Under this employment model, the company is willing to provide employees with long-term and stable employment protection, and employees are also willing to stay in the company for a long time, accompanied by relatively positive innovative behavior. American social psychologist Robert Eisenberger put forward a sense of organizational support on the basis of the principle of reciprocity through a series of studies on employee incentive mechanisms. When employees feel the support of the organization, they will be encouraged to show positive employee behavior. For example, Ling Wenzhen and others believe that, from the perspective of employees, continuing to stay in the organization and continue to make behaviors that are conducive to organizational performance is inseparable

Table 2. Influencing factors of employee innovation behavior.

\begin{tabular}{|c|c|c|c|}
\hline Research level & Research factors & Conclusion & Author \\
\hline Individual level & $\begin{array}{l}\text { Personality traits, emotions, roles, cognitive } \\
\text { style, intrinsic motivation (psychological } \\
\text { empowerment, self-efficacy, work } \\
\text { emotions), professional knowledge, creative } \\
\text { thinking skills }\end{array}$ & $\begin{array}{l}\text { Individuals with distinctive personality traits are } \\
\text { positively correlated with individual innovation } \\
\text { behavior; intrinsic motivation drives innovation } \\
\text { behavior }\end{array}$ & $\begin{array}{l}\text { Amabile (1998); } \\
\text { Woodman, Sawyer, \& } \\
\text { Griffin (1993) }\end{array}$ \\
\hline Organization level & $\begin{array}{l}\text { Organizational factors (organizational } \\
\text { culture, resources and salary, strategy and } \\
\text { skills) }\end{array}$ & $\begin{array}{l}\text { Work factors and organizational factors have an } \\
\text { impact on employees' innovative behavior }\end{array}$ & $\begin{array}{l}\text { De Cuyper \& De Witte } \\
\qquad(2009)\end{array}$ \\
\hline $\begin{array}{l}\text { Interaction between } \\
\text { individuals and } \\
\text { organizations }\end{array}$ & $\begin{array}{l}\text { Situation and social environment factors, } \\
\text { work emotions and supportive work } \\
\text { environment, team learning behavior and } \\
\text { employee learning orientation, } \\
\text { person-environment matching angle }\end{array}$ & $\begin{array}{l}\text { In a supportive work environment, when both } \\
\text { positive and negative emotions are at a high level, the } \\
\text { employees' performance of innovative behavior is } \\
\text { the strongest; team learning behavior and employee's } \\
\text { learning orientation will interact with employees' } \\
\text { innovative behavior; the degree of matching between } \\
\text { people and the environment will be Affect } \\
\text { employees' innovative behavior }\end{array}$ & George \& Zhou (2001) \\
\hline
\end{tabular}


from the importance the organization attaches to employees and organizational support. Organization-centric (mutual investment) employment model is a good example of organizational support for employees. In this process, the continuous employment model with no fixed-term labor contract is also an important form of organizational support, which effectively promotes the psychological safety of employees' out-of-role behavior. As pointed out by Morrision, if an employee's advice will be recognized and materially or emotionally rewarded by the organization, then the employee tends to think that the organization's employment environment is inclusive and risks If it is lower, it will show more positive advice than before. The research of Duan Jinyun also reached a similar research conclusion. Supportive organizational atmosphere and environment are conducive to employees to put forward innovative ideas and produce positive suggestions. The mutual investment-type employment model is an important manifestation of a supportive organizational environment. At the same time, employees' organizational citizenship behaviors, mutual assistance with colleagues, behaviors such as advocacy behaviors, etc., are positively influenced by the mutual investment-type employment model. With greater influence, these out-of-role behaviors can help provide employees with interpersonal relationships and promote organizational change and development.

Although individual employees may show different employee behaviors due to different organizational employment models, their internal influence mechanism or degree of influence still needs to be researched and improved. The study of Stamper and Masterson (2002) pointed out that the fixed-term employment model will have a significant impact on the organizational citizenship behavior of organizational members. Coyle-Shapiro and Kessler (2000) found that permanent employees showed more altruistic behaviors, and temporary employees showed less altruistic behaviors. Since organizational citizenship behavior is generally expected by the organization, it is conducive to improving organizational performance, which means that the employee's organizational citizenship behavior is the altruistic behavior that the employee produces for a considerable period of time. However, if the relationship between employees and the organization changes during this period of time, and expectations for the organization decrease, it is likely to reduce their altruistic behavior at work. However, some researchers have come to the opposite conclusion. For example, Pearce pointed out that temporary employees show more positive off-role behaviors, while permanent employees do not. As far as the exchange relationship between employees and organizations is concerned, the reciprocity between the two can affect the altruistic behavior of employees to a certain extent, but altruistic behavior will be affected by many factors, and reciprocity cannot be the only one between the two. It is also necessary to study the mechanism of temporary employment on altruistic behavior.

Furthermore, when the reciprocal relationship between employees and the organization reaches a minimum, they may think that their employment rela- 
tionship with the organization will not be maintained for too long and tend to give up their impression management in the organization. Kramer and Jenkins pointed out that temporary employees, especially short-term emergency temporary employees, pay little attention to their evaluation and impression in the organization. This less impression management is not conducive to the improvement of employees' work ability while reducing the expected work pressure of the individual; it is conducive to the organization to more accurately grasp the movements of employees for the organization, and it will reduce the extra effort for the organization, it is manifested in less altruistic behavior and extra-role behavior. Therefore, due to career planning considerations, temporary employees will also attach importance to reciprocal exchanges with the organization, and attach importance to their own work performance and evaluation in the organization (Arthur \& Rousseau, 1996).

2) Related Research on the Perspective of Employee Behavior

Foreign scholars mainly discussed the formation mechanism of organizational citizenship behaviors exhibited by various types of employees in the employment relationship from two perspectives. One perspective is to start with the relationship between employees and organizations and continue to the basis of social exchange theory. For example, Coyle believes that employees' organizational citizenship behavior has nothing to do with their employment model. As long as employees and organizations have reached a positive exchange and reciprocity model, they will encourage employees to generate positive voluntary social exchange behaviors, that is, organizational citizenship behavior, fixed there is no significant difference in the specific formation mechanism of positive behavior between employees with two types of employment, term and no fixed term. From this perspective, similar formation mechanisms exist in organizations with relatively consistent types of employment, but in organizations with a large number of types of employment, especially in companies or organizations that include dispatched employees or seasonal temporary workers, etc. In the meantime, such employees will also face the exchange mechanism between multiple groups, and may be excluded from the formal employees' work status or status discrimination, which may affect the organization of citizen behavior. Another perspective explores whether temporary employees' self-professional identity will have a significant impact on the formation mechanism of employees' extra-role behaviors. This perspective believes that employees with professional membership in a certain industry, even if they are temporarily hired, will think that they have a natural responsibility for the development of this industry, and it is necessary to improve their work ability and professional skills to promote the industry The healthy development of the organization, at the same time, this perspective is also a continuation of the view of professional practices.

3) Employee Motivation and Expectation Perspective

Few researchers have investigated possible moderating factors between temporary employment and employee behavioral outcomes. Some people emphasize 
that the motivation of temporary workers to obtain permanent jobs is highly predictive psychologically, and may even be more predictive than that of permanent employees. Temporary workers may be more keenly aware of "close to sight" opportunities than permanent employees. They will use these opportunities to demonstrate good organizational citizenship behavior even under non-optimal working conditions. Although this is obviously different from the motivation for accepting temporary work, it does not affect employees' acceptance of temporary work. Work motivation issues are relevant to both temporary and permanent employees. Facing current temporary jobs, temporary employees are also likely and likely to adjust their expectations downwards, or compare their current employment status with previous unemployment experiences, which may lead to a favorable evaluation of temporary employment, thus Encourage them to show unusually positive innovative behaviors for a certain period of time in order to keep the job, or even to be positive. Research on job security proves this: although low job security has a negative impact on fixed-term employees, it will not have too many negative effects on other types of temporary employees. In the past research, there is another possibility. Although job security is very important for regular employees, it is also possible that some temporary workers do not expect job security at all, so they will not have too positive work behaviors.

\subsubsection{Employment Model and Intra-Role Behavior}

The job role generally contains many responsibilities and obligations. It basically develops along two continuous dimensions: social embedding and formalization. The dimension of social embedding is a continuum, ranging from "lack of social interaction" to "love of social interaction". Tasks that lack social interaction are usually tasks that the task bearer can complete alone. If the task requires coordination by one or more people, this task requires social embedding. Tasks that lack social interaction usually require employees to provide more spontaneity or creativity than authoritative organizations. Nicholson (1984) based on employee career transition theory and role transition theory, raised questions about employee role innovation in the career transition process. By studying personal changes and role innovations, he believes that there are four modes of adaptation: absorption, exploration, replication and determination. When the work has a high degree of novelty and freedom, employees are willing to change them and have a high degree of innovative behavior.

The different employment modes of the organization will be directly reflected in a series of human resources and management procedures such as recruitment and training, which will have an impact on employee behavior. So, how does the employment model affect the behavior of employees? Role theory holds that social relations have an important influence on human behavior. Based on role theory, it can be assumed that employees will act according to the expected role information of employees in the organization's employment model. Some re- 
searchers have confirmed through research that the organization's management practice will be affected by the employment model, and the employee's behavior will be affected by the management practice. Combining role theory can explain the obvious differences between different employment modes, and the role connotation of employees will also be different.

With the continuous development of the economy, the labor market has formed two main modes of employment. The first kind of labor market relies more on the price mechanism, common temporary employment has strong flexibility, employees have low loyalty to the enterprise, there is not too much dependence on the enterprise, and naturally there will not be too much innovation Behavioral performance. If employees have better job choices, they are likely to leave the current organization; the second is similar to long-term employment, which is configured by the internal mechanism of the enterprise. This employment model has poor flexibility and the loyalty of general employees will be higher. He has a strong sense of attachment to the company and will voluntarily leave the company on rare occasions. Morrison and Phelps (1999) found that employees who are highly dependent on the organization have a strong sense of contribution to their own organization and will strive to show more behaviors that are beneficial to the organization. In a word, the different employment modes will directly lead to different employee roles through internal management practices, and the different employee roles will lead to different employee behaviors.

In summary, The above contents mainly explain 1) the different research conclusions of the employment model concepts and categories, the employment model and employee behavior, and the relevant research conclusions of the employment model as the adjustment mechanism; 2) the definition and scope of the employee innovation behavior concept, the employee innovation behavior Dimensions, and summarizes the influencing factors of employees' innovative behavior; 3) research on the relationship between the employment mode and the behavior outside the role of the employee from various angles, and based on the role theory, the relationship between the employment mode and the behavior inside the role of the employee.

\section{Mechanism of Employment Mode's Influence on Employees' Innovative Behavior}

\subsection{Theoretical Basis}

\subsubsection{Social Identity Theory}

Social identity theory believes that the self-definition of an individual is a method of classification by following self-sustainment, self-reinforcement and self-discrimination. According to the theory of social identity, individual behavior is affected by group members. When a person sees himself as a member of a group, he or she will have positive or negative emotions and attitudes towards that member. Once an individual defines his own identity as a member of a 
group, the individual's sense of social identity arises from this, and the individual takes the initiative to link his own personal interests with the collective interests of the organization and stands in the perspective of the organization and considers the issues.

\subsubsection{Social Exchange Theory}

Employees work to obtain material remuneration, which is the core of reciprocity in social exchange theory. From the perspective of social psychology, employees will hope that in the process of social exchange with the organization, the organization will pay more attention to their treatment and their efforts for organizational development, and the principle of reciprocity. As the core of the social exchange process, the principle of reciprocity promotes the formation of corresponding behaviors of individuals. Eisenberger pointed out that the principle of reciprocity includes positive and negative reciprocity. Employees receive organizational support and use voluntary and positive behaviors to give back. This can also be done by means of "social exchange" and "economic exchange".

\subsubsection{Work-Stress Theory}

Stress is an individual perception to some extent. Work-stress theory points out that under the interaction of subjective and objective factors, stress affects the individual, and stress starts from the pressure source to produce a sense of pressure, which in turn leads to a series of behavioral responses of the individual. Most research shows that work stress has a negative impact on individuals. Lazarus (1993) believes that factors such as emotional overload, unbalanced income and expenditure, personal and work mismatches, inconsistent values between employees and the organization, and other factors that threaten employees and cannot be handled can form stressors. Low job security is a common source of stress one. The "requirement-control" model is the most commonly used model in work-stress theory (Karasek \& Theorell, 1990). When the work requirements of employees exceed the scope of the role of the employees, and the organization gives very little support, you will feel a deep sense of the pressure from work. The insecurity associated with the employment model in this model can cause greater pressure on employees. At the same time, the innovative behavior of employees will also be affected.

\subsection{Variable Selection}

\subsubsection{Independent Variable}

Existing research shows that temporary employment has fixed-term labor contracts, labor agency contracts, seasonal or fixed-term labor contracts, and other forms. This article focuses on the employment model of permanent employment, that is, a labor contract with no fixed term, and one of the types of temporary employment-fixed-term labor contract.

First, the lack of distinction between subcategories makes it difficult to reach 
consensus, focus on specific differences, and find out where the problem lies. Many authors believe that the heterogeneity of the temporary employment model may be the reason for the inconsistent results of various studies and discussions. Different researchers have highlighted the huge differences between specific types of temporary employment models, most notably in terms of employment stability, and demographics such as age, nature of work, education and tenure among employees in similar positions Variable aspects (Cohany, 1998). Specifically, directly hired fixed-term contract workers are considered to be most similar to permanent employees. Temporary agent workers, especially temporary workers and on-call workers may occupy the most marginal positions.

Secondly, compared with other temporary employment types, fixed-term employees have their own unique characteristics: employees with fixed-term labor contracts are directly hired by employers, without professional intermediaries, and the employment method is relatively simple; fixed-term and unfixed-term On the surface, this employment model differs only in the duration of employment, which is different from some types of temporary workers, such as seasonal or self-employed. Although the duration of the employment duration may also lead to other differences, such as the value status of employees in the company, the relationship between employees and the company, and the long-term social recognition of employees and the company, this will directly affect the organizational identity and work of the employees Security. However, fixed-term employment is still the closest to the characteristics of permanent employment among all types of temporary employment. And our country's laws also stipulate the relevant provisions for signing the third fixed-term labor contract to become an unfixed-term labor contract. In a sense, fixed-term employment is the early stage of unfixed-term employment. It is the unique relationship between the two that makes these two types of employment models more valuable to a certain extent.

Finally, although new employment methods such as labor intermediaries and labor agents continue to emerge, the most important type of employment in the temporary employment model is still fixed-term employment. In today's world, the fixed-term employment model is the most important and popular temporary employment method at home and abroad. Therefore, this paper chooses two employment modes of fixed-term labor contract and non-fixed-term labor contract from the perspective of organizational identification and employees' work safety to compare the impact on employees.

\subsubsection{Dependent Variable}

In this paper, in terms of the choice of outcome variables, this paper pays more attention to employee innovation behaviors that are specific behavior variables that can bring immediate benefits to the organization, such as employee advocacy behaviors, organizational citizenship behaviors, role innovations and other related variables. These are more meaningful to the organization. 
The concept of advocacy behavior was first proposed by Hirschman (1970). He believed that advocacy behavior is a way for employees to express dissatisfaction with the organization. Van Dyne classified advisory behavior as a challenge-promoting organizational civic behavior category. In 1998, it defined "voice" as the extra-role behavior of organization members who are willing to put forward constructive opinions in order to improve the organization's work or current situation, which belongs to the category of interpersonal communication. The recommendations made by Linn Van Dyne, Soon Ang, Isabel C. Botero (2003) refer to the practice of employees helping their organizations to innovate and successfully adapt to the changing business environment, that is, constructive ideas, concerns, or concerns that raise work-related issues. There are many behaviors that affect advice. Generally speaking, the process in which employees decide to adopt advice is affected by individuals, organizational situations, and leadership behaviors. At present, in addition to demographic variables, the antecedent variables that have been certified by research include organizational identity, self-efficacy, and role perception. On the basis of Chinese cultural background, Liang and Farh (2012) further proposed that advocacy can be divided into two dimensions: promotion and inhibition. It also verifies the influence of psychological security on advice behavior and the interaction between the three. The results show that the sense of constructive change has a significant positive impact on promotion advice, while inhibitory advice is more affected by work safety. Venkataramani and Tangirala believe that employees with higher organizational identity will actively participate in advocacy.

As for organizational citizenship behavior, generally speaking, the requirements of the organization on employees are reflected in the recruitment conditions before the start of the job and the description after the start of the job. But for some employees, even if the organization does not require them, they will actively make behaviors that are beneficial to the organization or colleagues. Organ (1988) refers to this type of behavior as organizational citizenship behavior, which is defined as "informally specified in the job description, non-mandatory, not rewarded by the organization, and critical to the success of the organization". Later, Organ redefined it as "not only refers to non-duty behavior, but also provides maintenance and improvement for the organizational environment". Organizational citizenship behavior includes recognition of organizational values and vision, altruistic behavior among colleagues, initiative, and protection of company interests. Although organizational citizenship behavior is not explicitly authorized by the organization and can be freely determined by the organization, in the long run, this behavior can promote the operation of the organization and improve the creativity of employees. Smith and Organ believe that organizational citizenship behavior can help improve organizational effectiveness regardless of whether it is rewarded by the organization. Subsequent research has also continuously confirmed that organizational citizenship plays an important role in achieving organizational goals. 
Role innovation is to introduce important new behaviors into pre-existing roles in the context of job changes and job changes. If the working style of the current position is different from that of the predecessor, this is considered a role innovation. Role innovation is related to innovative behavior. It is an innovative behavior to introduce new behaviors and procedures into existing job roles. Role innovation is to change a process or improve a program in an individual's job role. Innovative behaviors occur not only in jobs, but also in departments and organizations.

The above three innovation variables are in line with the characteristics of employee behavior that can bring immediate changes to the organization. Therefore, this article selects two specific individual innovation behaviors as intra-role innovation (role innovation) and extra-role innovation (advice, organizational citizen behavior) result variables to study. After the previous analysis of the importance and influencing factors of employees' innovative behaviors, a comprehensive study shows that many scholars have made important progress in the field of innovative behaviors, but there are still many issues worthy of in-depth research. In management practice, individual employees work in an organization, so individual creativity is also affected by organizational characteristics. Therefore, to study the innovation ability of employees not only needs to identify employees with innovation ability, but also needs to consider the influence of organizational characteristics such as the employment mode adopted by the organization on individual innovation ability.

\subsubsection{Other Variables}

This paper believes that to explore the mechanism of the effect of the employment model on employee innovation behavior, a conceptual model that can clearly express the influence mechanism in more detail is needed, focusing on being clear and specific to the variable level. In terms of control variables, not only should demographic characteristics such as employee gender and education level be considered, but also contract feature variables such as employee position in the enterprise and the number of contract signings; at the same time, comprehensive consideration should be given to the characteristics and manifestation of the fixed-term contract itself variables of employee-enterprise relationship, such as organizational identity and job security; pay attention to the impact of the employment model on employee response, not only regard the employment model as an independent variable, but also consider its relationship between the fulfillment of corporate psychological contract and employee innovation behavior Regulation effect.

Most of the current research on the role of employment models only focuses on one of these types, and it is not systematic enough in the study of the mechanism of action. This study believes that we must first analyze clearly the characteristics of various types of employment and their respective job formation mechanisms. Second, we must consider the impact of the employment model on 
the relationship between employees and the organization. Finally, after employees sign a labor contract with the organization and enter the organization, they will experience work pressure and socialization of the organization, that is, the process of social identification and exchange. Therefore, this study explores the effects of independent variables on dependent variables through social exchange processes, work-stress processes, and social identification processes. From the perspective of the selection of related variables, employees' sense of belonging to their organization is mainly reflected in organizational identity. Therefore, organizational identity is selected to explore whether the social identification process differs between different employment models. In addition, psychological contract variables are divided into transactional, relational, and balanced dimensions. Therefore, choosing a psychological contract can verify and discuss the exchange process between the organization and employees from multiple dimensions. At the same time, the limited duration of the fixed period will bring greater pressure on employees to feel safe at work. Under this kind of pressure, relatively negative behaviors will occur, so choose work safety to explore the impact of the work-stress process on employees with fixed deadlines. As shown in Table 3, the characteristics of the three action mechanisms reflect certain comprehensiveness, which is beneficial to the analysis and research of this article.

\subsection{Mechanism of Employment Mode's Influence on Employees' Innovative Behavior}

\subsubsection{Intermediary Mechanism Based on Work Safety}

Earlier studies on the definition of job security felt that it focused on the continuity and indefinite nature of the employment relationship. The low sense of security of the continuity of work mainly includes two meanings. On the one hand, the uneasy feeling of losing the job or the ability to work on the surface; on the other hand, with the development of society, the unique work characteristics of the work itself may be in the future Anxiety that will disappear. Therefore, low job security does not mean that employees will lose their jobs. The

Table 3. Summary of variables and characteristics of work-stress, social identification and social exchange mechanism.

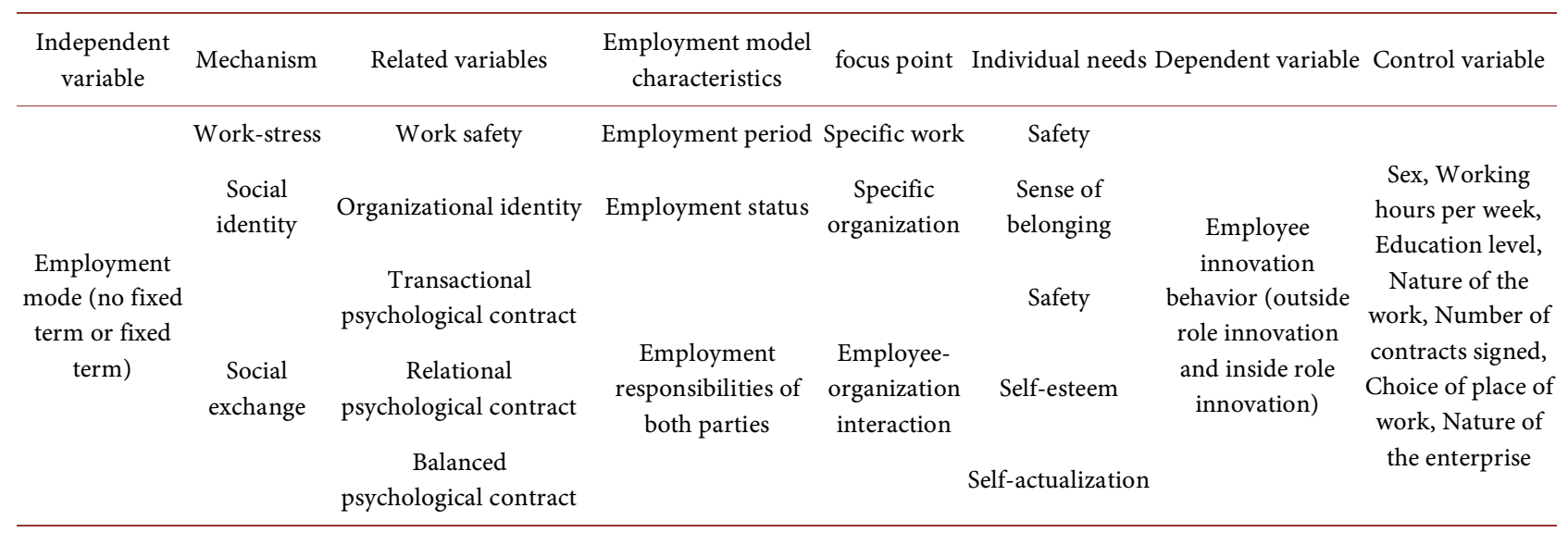


sense of work safety of employees in daily work means that employees believe that their work in the organization is sustainable, without having to worry about being fired by the company, which is also the organization's long-term commitment to hiring employees.

Research on the antecedents of job security is largely related to dismissal, which is mainly reflected in major structural changes that may occur in the company, such as company acquisitions, mergers or bankruptcy dissolution. Due to external reasons, such as irresistible objective reasons such as epidemic situations, the company may dismiss employees in order to reduce labor costs. Brockner (1988) research pointed out those employees who have not yet been terminated by the company's labor contract will also be psychologically affected by their layoffs in terms of their job security. Stress theory points out that the causes of employee anxiety are often their expectations and psychological perception of stress-related events that trigger stress and roles (Lazarus \& Folkman, 1984). Some scholars have shown that work safety may affect the mental state of individual employees, which in turn affects their behavior in the organization. Some researchers show that job security has an impact on organizational citizenship behavior. The research results of Chinese scholars Zhang Hong and Zhao Shuming prove that hiring guaranteed employees, that is, the safer the employees' work, the more beneficial to the organization's civic behavior and the greater the trust in the employees.

Many researchers have confirmed that temporary employment is likely to produce low job security. As for the employment model, the fixed-term model is also true. Heponiemic studied the data of Finnish female medical staff and found that after controlling the nature of the organization as a control variable and avoiding the interference of its impact, the degree of job security of fixed-term employees is significantly lower than that of permanent employees. The data research in the Netherlands and the conclusions found by Saloniemi \& Zeytinoglu (2007) on the statistical data of Finland and 1994 in Canada are consistent. In addition, in an organization with many temporary employees, if regular employees interpret the temporary employees' presence as management's intent to change internal structures or identify qualified job candidates, they may continue to perform negatively and without performance. To respond, Kraimer found that fixed-term employees with low job security are not less likely to believe in the motives of organizations to hire temporary employees, nor do they feel obligated to perform well. In contrast, those with a high sense of job security are more likely to actively evaluate the organization's intentions and reward the organization with good behavioral performance. Although most scholars such as Feather, Rauter and Yeh recognize that employees' work safety will be affected to a certain extent by the type of employment model, which in turn affects employees' different levels of innovative behavior. However, few studies have used it as an intermediary variable to study its relationship with employment patterns and employee behavior. 
The fixed-term contract and the non-fixed-term contract stipulate that the employment period is different, the former has a term, and the latter is permanent. The fixed-term employees agree on the validity of the contract with the organization. Such employees may face the risk of losing this job in the future, which may cause employees to feel higher work pressure. Most scholars believe that this source of stress can be expressed in terms of job security. The sense of job security is employees' perception of their continuous work. The terms of the fixed-term contract it will affect employees' psychological perception of job security. Therefore, compared with job security for permanent employees with unlimited renewal, employees with a fixed period of time are likely to feel a lower level of job security, which may lead to negative innovative work behaviors.

\subsubsection{Intermediary Mechanism Based on Organizational Identity}

Social identity theory believes that individuals in human society tend to exist in the form of groups. Organizational identity derives from the theory of social identity. The definition of organizational identity is divided into broad and narrow definitions. The broad definition includes individual value and organization. Consistency, and perception of the relevance of organizational identity; the narrow definition holds that the organizational identity of employees is a symbol of employees belonging to the organization. This article believes that organizational identity is an individual employee's perception of their sense of dependence and trust in their organization. Early scholars paid more attention to what kind of organizational factors and individual factors will affect organizational identity, such as Smidts, Pruyn and Van Riel (2001). Later, some scholars have shown that the interaction between individuals and organizations will also affect organizational identity. Employee's organizational identity will have a positive impact on their behavior; this conclusion has been confirmed by most studies. Most studies confirm that organizational identity has a positive effect on employee behavior, which in turn affects organizational output.

At present, most of the existing research is based on "employees with different employment modes are treated by different organizations, so different organizational identities are generated". They explained the impact of the employment model on organizational identity, but did not see a specific formation mechanism similar to self-reinforcement, maintenance, and discrimination that generated organizational identity. Under the framework of these three mechanisms, the analysis of how the employment model makes employees different Degree of organizational identity. Rousseau defines the organizational identity of temporary employees in a contextual way, deeply defines the organizational identity of permanent employees, and points out that different levels of organizational identity may exist among employees with different employment patterns. Koene and Van Riemsdijk (2005) also pointed out that employees' varying degrees of organizational identity will be affected by the type of employment, and proposed different human resources management policies for temporary employees and 
long-term employees. There are few empirical studies on the impact of employment patterns and organizational identity. Only Buonocore (2010), after surveying employee data of several hotels in Italy, found that there is a large difference in the degree of organizational identity between informal and formal employees, and employees' emotional commitment to the organization will be affected big influence, etc. In addition, Prithviraj Chattopadhyay and Elizabeth George (2001) observed that only permanent workers working in groups dominated by temporary workers will be negatively affected. Broschak and Davis-Blake (2006) also proved the relationship between the degree of heterogeneity of the employment arrangements in the work group and the employee's turnover tendency, and the relationship between the heterogeneity of the employment relationship and the poor relationship between supervisors and colleagues At the same time, it is believed that the dominance of temporary workers may threaten the high prestige of permanent employees and a positive high organizational identity.

Social identity is the individual's own positioning in the society and self-perception of certain social identities. It is mostly expressed as organizational identity in the employment relationship between organizations and employees. This article believes that the employment model can directly affect the degree of employee's organizational identity in the enterprise, and then affect the employee's innovative behavior through the employee's self-internal "internal personnel" status perception. This process is reflected through the uniqueness of different types of employment models, such as the duration of contracts with fixed-term and non-fixed-term employment models, and the deep status of employees in the enterprise caused by the duration, employees and corporate relationship orientation and long-term social recognition. To a certain extent, the social and organizational identities of employees with no fixed term generally exist permanently, while the social and organizational identities of fixed-term employees terminate after the expiration of the contract. Therefore, employees who obtain an indefinite contract are more likely to have a high degree of organizational identity and social identity as a member of the organization; employees who sign a labor contract with the organization for a limited period of time will have a lower sense of organizational identity. As a result, these two types of employees will exhibit different roles of internal and external innovation behavior.

\subsubsection{Adjustment Mechanism Based on Psychological Contract}

The concept of psychological contract was introduced into the management field in the early 1960s. In the relationship between employees and organizations, in addition to the contents of the formal employment contract, there are implicit mutual expectations of both parties, which are also important to affect employee behavior factor. Levinson believe that psychological contracts are the sum of implicit and undisclosed mutual expectations between organizations and em- 
ployees. Kotter defines a psychological contract as an implicit agreement between an individual and an organization. The agreement specifies that one party expects the other's effort and gain in the relationship. Schein defines it as "a series of unexplained expectations that exist between individuals and organizations at any time". Rousseau proposed that psychological contract is recognition of the mutual responsibilities and obligations of both parties of the employment. As a party to the contract, the organization only provides the background and environment for forming the psychological contract. The organization itself does not have the cognitive processing to construct the psychological contract. Process, therefore, in essence, the psychological contract in the employment relationship is the perception of the individual employee on the exchange relationship between himself and the enterprise. Psychological contract fulfillment and psychological contract rupture are contract concepts often studied by scholars. The actual fulfillment level of an enterprise's psychological contract actually represents whether the enterprise's actual responsibility commitment is fulfilled, which is very similar to the incentive level in the incentive-contribution model.

The existing research results on the contract structure are inconsistent and can be divided into two-dimensional structure theory and three-dimensional structure theory. Macneil proposed the two-dimensional structure of the psychological contract. He believes that the psychological contract is on a continuum of transition from transactional to relational. After him, many scholars have devoted themselves to the study of psychological contract types. Rousseau divides psychological contracts into four types according to the two dimensions of performance requirements and time structure: transactional, relational, balanced and transformative. Relational psychological contract is a long-term employment arrangement based on mutual trust and loyalty. Employee rewards are mainly based on their relationship with the organization; transactional psychological contract focuses on short-term economic contract exchange between employees and the organization; balanced psychology the contract is between the two, and has certain characteristics of economic exchange and social exchange; and the premise of the transformational contract has its own special features. Although Rousseau calls the transformational psychological contract also as a psychological contract, she believes that this does not a true psychological contract, but a cognitive state, which reflects the breakdown of the relationship between employees and the organization after the organization changes. Therefore, transactional, balanced, and relational psychological contracts represent an important type of psychological contract in the employment relationship. This article will not study transformative psychological contracts.

Existing research on psychological contracts focuses on the impact of corporate psychological contract fulfillment or breakdown on employees, as well as other intermediary variables that may exist between them. However, there are few studies on the employment model, such as the indirect impact of the em- 
ployment model on the relationship between psychological contract and employee behavior. When employees believe that the company has fulfilled good psychological contract responsibilities, social exchange theory shows that employees will have positive evaluations and behaviors on the positive relationship between employees and organizations, and the principle of reciprocity in social exchange theory shows that employees' positive behaviors will Increasing the commitment to the organization, otherwise, it produces negative evaluations and behaviors, reducing the commitment to the organization, and most existing studies have confirmed this. At the same time, some studies have shown that the organizational citizenship behavior of employees will be affected by the actual fulfillment of corporate psychological contracts; Psychological contract fulfillment will produce positive innovative behavior, and the destruction of psychological contracts will lead Negative anti-production behaviors, such as theft, reduce employee innovation behaviors, such as Ng, Feldman, \& Lam (2010). Existing research has drawn different conclusions on the impact of employment models on the fulfillment of corporate psychological contracts. Compared with long-term employees, one type of research found that temporary employees have a lower level of corporate psychological contract fulfillment or a higher degree of psychological contract breakdown, and another study considers temporary Employees have a higher level of corporate psychological contract fulfillment and a lower level of psychological contract breakdown. As the Guest (1998) Institute found, some employees gave more positive and non-negative feedback and evaluation of the organization's psychological contract status. Such employees are knowledge employees hired for a fixed period of time. The reason may be that the psychological contract exchange between such employees and the organization is a transactional psychological contract. However, there are studies showing that there is no significant difference between the two.

The process of social exchange shows the economic and emotional exchange between employees and organizations, which is essentially the fulfillment of the responsibilities and obligations of both parties. Previous studies have focused more on the direct impact of the employment model, whether companies treat employees of different types of employment models equally and equally, and whether different types of employees can feel the same concern and care of the company. Does the organization actually fulfills its support responsibilities and committed to. However, the impact of the strength of social exchange content on employees is often overlooked, and the psychological contract that focuses on the perception and fulfillment of corporate and employee responsibilities reflects the strength of social exchange content between organizations and employees, and therefore has unique research value. This paper analyzes the three-dimensional contract structure proposed by Rousseau and Wade-Benzoni (1994), with a view to exploring the role of psychological contract in a more comprehensive way. On the one hand, this article explores the direct impact of the employment model on the psychological contract. On the other hand, although employees with differ- 
ent employment models can directly perceive the actual performance of the enterprise's psychological contract, the results of the enterprise's psychological contract are relatively vague and employees cannot Clearly explain the degree of organizational performance that the company's psychological contract performance should produce and the degree of employee innovation behavior. Therefore, enterprises should pay attention to the indirect impact of employment model on psychological contract mechanism. Among them, whether the employment model will play a regulatory role is the focus of this research model.

In terms of the employment model's impact on the actual fulfillment of the psychological contract, this article believes that the actual fulfillment of the employee's psychological contract is closer to the incentive-contribution model, focusing on the actual paid value of both the enterprise and the employee. According to social exchange theory, employees will give positive feedback to the positive treatment of the company; otherwise it will be negative feedback. The realization of the company's actual commitment to the employee's contract and commitment, and the employee's psychological perception of this will prompt the employee to produce positive innovative behaviors; and if the contract and commitment are not realized, it will also trigger the employee's retaliatory employee psychological contract to break and trigger negative employee innovation behavior. Employment mode will act as a moderating variable.

\section{Analysis Conclusions}

Management practices have proven that many companies achieve good organizational performance by stimulating individual employees' innovative behaviors at different levels and levels. Based on the review of previous research on employment model and employee innovation behavior, this paper discusses the employment model in the process of social exchange, social identification, and work-stress based on social exchange theory, social identification theory, and work-stress theory The mechanism of the impact of employee innovation behaviors has proposed three ways in which the employment model affects employee innovation behavior, and on this basis, a conceptual model is proposed. The employment model has an impact on employee innovation behavior through work safety and organizational identity; in the relationship between the actual performance of the contract and the employee's innovative behavior, the employment model will have a corresponding adjustment effect, as shown in Figure 1.

\section{Research Significance and Research Prospect}

\subsection{Significance}

This paper builds a model of the mechanism of employment mode and employee innovation behavior, enriches and improves the theoretical research results of employee innovation behavior. This provides a theoretical basis for 


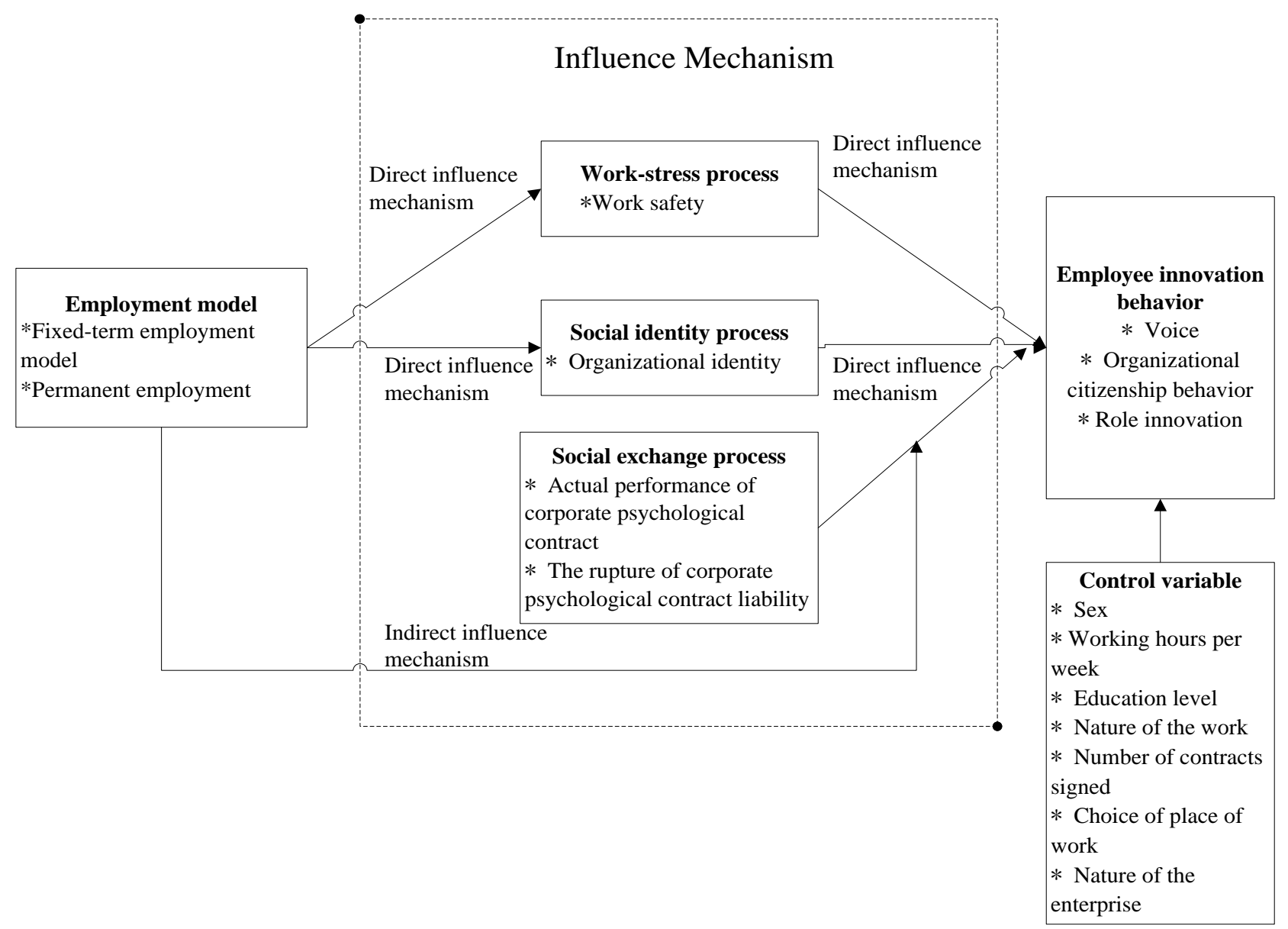

Figure 1. The mechanism of the employment model's impact on employees' innovative behavior.

companies to explore and select employment cooperation models suitable for a win-win situation between employees and organizations in innovative practices. Employee innovation behavior is a very important part of research in the field of innovation, and many researchers have elaborated various relevant variables. At present, the research on the employment model and employee innovation behavior in China's academia is still in the stage of continuous improvement. At present, there is very little research on the employment model for employee innovation behavior by triggering employees' psychological mechanisms in China. It is worth exploring the problem, the construction of the model is to further improve the theoretical results between the two.

This article explores the formation mechanism of employees' innovative behavior from the perspective of employees' psychological security and organizational identity. Existing innovation research usually studies the direct impact of the employment model on employee behavior, ignoring its inherent essential characteristics, and often stays at the organizational level, failing to deeply analyze the psychological formation mechanism of employee innovation behavior at the employee level. This article explores the formation mechanism of innovative behaviors from the perspective of employee-level psychological security and or- 
ganizational identity, and believes that work security and organizational identity are the concrete manifestations of employees' perception of organizational support in their work, while it will be affected by the employment model. This study systematically reveals the internal mechanism of the formation of employment model and employee innovation behavior. This article explores the moderating role of the employment model in the fulfillment of corporate psychological contracts and employee behavior. Fixed-term employees have a low psychological dependence on the company and a shorter employment relationship with employees, resulting in differences in employee responses to company behavior. It helps to promote companies to actively fulfill their psychological contractual responsibilities to employees, strengthen communication with employees, provide reference for human resources practice, and give different strategies to employees with different employment models.

For enterprises, it is helpful for enterprises to actively seek reform and innovation to resist the unpredictability of the external environment of the labor market. Seize market opportunities to constantly reform and innovate; prompt enterprises to actively explore employment modes for flexible employment, and promote cooperation and mutual benefit between enterprises and employees. For individual employees, in the face of changes in the labor market, the most important thing is to keep the skills of the job, followed by the skills to find the job, and finally the job skills; in addition, the choice of employment mode, in addition to considering stable and secure employment In addition to the model, you can also actively seek a flexible and cooperative employment model with the enterprise, seize the opportunity, pursue transformation and innovation, and make you have more employment options.

\subsection{Research Outlook}

First of all, regarding the variables of employee innovation behavior, previous researches mostly measured the concept and dimensions from the perspective of innovation process. This article defines its concept and dimensions from the perspective of innovation results, but does not combine specific industry characteristics and organizational size for analysis. In response to this, the future should combine the local cultural context and the characteristics of the Chinese enterprise organization paradigm in the context of the Internet to further explore the composition of individual employees' innovative behaviors, and jointly measure from the perspective of process and results. At the same time, considering the influence of factors such as the industry background of the organization, the size of the organization, the characteristics and structure of employee members, and more precise consideration of the composition and differences of employee innovation behavior under different conditions.

Secondly, this article puts forward a conceptual model based on the literature review, which has not been verified and improved through empirical research. In view of this point, future research is necessary to conduct empirical hypothesis 
testing on the model from a quantitative perspective in conjunction with a sample of Chinese companies, in order to more accurately guide the innovation management practices of companies. In addition, there are many kinds of psychological mechanisms. In addition to work safety and organizational identity, whether there are other psychological mechanisms that play an intermediary role need to be further discovered and confirmed. Existing research shows that organizational identity strengthens the relationship between work safety and employee behavior, and whether there is a certain interaction between other psychological mechanisms at different levels also needs to be explored and tested.

\section{Fund Project}

Funded by special funds for basic scientific research business expenses of central colleges and universities, project name: Research on the Model of the Use of Information Systems of Science and Technology Enterprises for Technology Innovation, Project Number: RW180174; Funded by the major theoretical and practical issues of the social sciences in Shaanxi Province (Project No. 2019C072).

\section{Conflicts of Interest}

The authors declare no conflicts of interest regarding the publication of this paper.

\section{References}

Amabile, T. M. (1998). How to Kill Creativity. Harvard Business Review, September/October, 77-87.

Arthur, M. B., \& Rousseau, D. M. (1996). The Boundaryless Career: A New Employment Principle for a New Organizational Era. New York: Oxford University Press.

Bernhard-Oettel, C., Sverke, M., \& De Witte, H. (2005). Comparing Three Alternative Types of Employment with Permanent Full-Time Work: How Do Employment Contract and Perceived Job Conditions Relate to Health Complaints? Work and Stress, 19, 301-318. https://doi.org/10.1080/02678370500408723

Brockner, J. (1988). Self-Esteem at Work: Research, Theory and Practice. Lexington, MA: D.C. Heath \& Co.

Broschak, J. P., \& Davis-Blake, A. (2006). Mixing Standard Work and Nonstandard Deals: The Consequences of Heterogeneity in Employment Arrangements. Academy of Management Journal, 49, 371-393. https://doi.org/10.5465/amj.2006.20786085

Buonocore, F. (2010). Contingent Work in the Hospitality Industry: A Mediating Model of Organizational Attitudes. Tourism Management, 31, 378-385. https://doi.org/10.1016/j.tourman.2009.04.005

Chattopadhyay, P., \& George, E. (2001). Examining the Effects of Work Externalization through the Lens of Social Identity Theory. Journal of Applied Psychology, 86, 781-788. https://doi.org/10.1037/0021-9010.86.4.781

Clinton, M., Bernhard-Oettel, C., Rigotti, T. et al. (2011). Expanding the Temporal Context of Research on Non-Permanent Work Previous Experience, Duration of and Time 
Remaining on Contracts and Employment Continuity Expectations. Career Development International, 16, 114-139. https://doi.org/10.1108/13620431111115596

Cohany, S. R. (1998). Workers in Alternative Employment Arrangements: A Second Look. Monthly Labor Review, 121, 3-21.

Connelly, C. E., \& Gallagher, D. G. (2004). Emerging Trends in Contingent Work Research. Journal of Management, 30, 959-983. https://doi.org/10.1016/j.jm.2004.06.008

Coyle-Shapiro, J., \& Kesslor, I. (2000). Consequences of the Psychological Contract for the Employment Relationship: A Large Scale Survey. Journal of Management Studies, 37, 903-930. https://doi.org/10.1111/1467-6486.00210

De Cuyper, N., \& De Witte, H. (2009). Temporary Employment: Associations with Employees' Attitudes, Well-Being and Behaviour. A Review of Belgian Research. Psychologica Belgica, 49, 249-273. https://doi.org/10.5334/pb-49-4-249

De Cuyper, N., de Jong, J., De Witte, H. et al. (2008). Literature Review of Theory and Research on the Psychological Impact of Temporary Employment: Towards a Conceptual Model. International Journal of Management Reviews, 10, 25-51.

https://doi.org/10.1111/j.1468-2370.2007.00221.x

De Graaf-Zijl, M. (2012). Job Satisfaction and Contingent Employment. Economist-Netherlands, 160, 197-218. https://doi.org/10.1007/s10645-011-9180-7

Gash, V., Mertens, A., \& Gordo, L. R. (2007). Are Fixed-Term Jobs Bad for Your Health? A Comparison of West-Germany and Spain. European Societies, 9, 429-458. https://doi.org/10.1080/14616690701314150

George, J. M., \& Zhou, J. (2001). When Openness to Experience and Conscientiousness Are Related to Creative Behavior: An Interactional Approach. Journal of Applied Psychology, 86, 513-524. https://doi.org/10.1037/0021-9010.86.3.513

Guest, D. E. (1998). On Meaning, Metaphor and the Psychological Contract: A Response to Rousseau. Journal of Organizational Behavior, 19, 673-677. https://doi.org/10.1002/(SICI)1099-1379(1998)19:1+<673::AID-JOB973>3.0.CO;2-Z

Hirschman, A. O. (1970). Exit, Voice, and Loyalty. Cambridge, MA: Harvard.

Janssen, O., \& Van Yperen, N. W. (2004). Employees' Goal Orientations, the Quality Leader-Member Exchange, and the Outcomes of Job Performance and Job Satisfaction. Academy of Management Journal, 47, 368-384. https://doi.org/10.5465/20159587

Karasek, R., \& Theorell, T. (1990). Healthy Work: Stress, Productivity, and the Reconstruction of Working Life. New York: Basic Books.

Koene, B., \& van Riemsdijk, M. (2005). Managing Temporary Workers: Work Identity, Diversity and Operational HR Choices. Human Resource Management Journal, 15, 76-92. https://doi.org/10.1111/j.1748-8583.2005.tb00141.x

LaMontagne, A. D., Smith, P. M., Louie, A. M. et al. (2012). Psychosocial and Other Working Conditions: Variation by Employment Arrangement in a Sample of Working Australians. American Journal of Industrial Medicine, 55, 93-106. https://doi.org/10.1002/ajim.21038

Lazarus, R. S. (1993). From Psychological Stress to the Emotions: A History of Changing Outlooks. Annual Review of Psychology, 44, 1-21. https://doi.org/10.1146/annurev.ps.44.020193.000245

Lazarus, R., \& Folkman, S. (1984). Stress, Appraisal, and Coping. New York: Springer.

Liang, J., \& Farh, J. L. (2012). Psychological Antecedents of Promotive and Prohibitive Voice: A Two-Wave Examination. Academy of Management Journal, 5, 71-92. https://doi.org/10.5465/amj.2010.0176 
Manville, C. (2008). Justice Perceptions and Organizational Commitment: Would Contingent and Permanent Workers Be Different? Industrial Relations, 63, 529-554. https://doi.org/10.7202/019100ar

March, J., \& Simon, H. (1958). Organizations. New York: John Wiley and Sons.

Mauno, S., Kinnunen, U., Makikangas, A. et al. (2005). Psychological Consequences of Fixed-Term Employment and Perceived Job Insecurity among Health Care Staff. European Journal of Work and Organizational Psychology, 14, 209-237. https://doi.org/10.1080/13594320500146649

Morrison, E. W., \& Phelps, C. C. (1999). Taking Charge at Work: Extra Role Efforts to Initiate Workplace Change. Academy of Management Journal, 42, 403-419. https://doi.org/10.2307/257011

Ng, T. W. H., Feldman, D. C., \& Lam, S. S. K. (2010). Psychological Contract Breaches, Organizational Commitment, and Innovation-Related Behaviors: A Latent Growth Modeling Approach. Journal of Applied Psychology, 95, 744-751. https://doi.org/10.1037/a0018804

Nicholson, N. (1984). A Theory of Work Role Transitions. Administrative Science Quarterly, 29, 172-191. https://doi.org/10.2307/2393172

Organ, D. W. (1988). Organizational Citizenship Behavior: The Good Soldier Syndrome. Lexington, MA: Lexington Books/D. C. Heath and Com.

Rousseau, D. M. (1989). Psychological and Implied Contracts in Organizations. Employee Responsibilities and Rights Journal, 2, 121-139. https://doi.org/10.1007/BF01384942

Rousseau, D. M., \& Wade-Benzoni, K. A. (1994). Linking Strategy and Human Resource Practices: How Employee and Customer Contracts Are Created. Human Resource Management, 33, 463-489. https://doi.org/10.1002/hrm.3930330312

Saloniemi, A., \& Zeytinoglu, I. U. (2007). Achieving Flexibility through Insecurity: A Comparison of Work Environments in Fixed-Term and Permanent Jobs in Finland and Canada. European Journal of Industrial Relations, 13, 109-128. https://doi.org/10.1177/0959680107073971

Scott, S., \& Bruce, R. (1994). Determinants of Innovative Behavior: A Path Model of Individual Innovation in the Workplace. The Academy of Management Journal, 37, 580-607. https://doi.org/10.2307/256701

Smidts, A., Pruyn, A. T. H., \& Van Riel, C. B. M. (2001). The Impact of Employee Communication and Perceived External Prestige on Organizational Identification. Academy of Management Journal, 44, 1051-1062. https://doi.org/10.5465/3069448

Stamper, C. L., \& Masterson, S. S. (2002). Insider or Outsider? How Employee Perceptions of Insider Status Affect Their Work Behavior. Journal of Organizational Behavior, 23, 875-894. https://doi.org/10.1002/job.175

Tak, J., \& Lim, B. (2008). The Differences in Career-Related Variables between Temporary and Permanent Employees in Information Technology Companies in Korea. Journal of Career Development, 34, 423-437. https://doi.org/10.1177/0894845308316294

Van Dyne, L., Ang, S., \& Botero, I. C. (2003). Conceptualizing Employee Silence and Employee Voice as Multidimensional Constructs. Journal of Management Studies, 40, 1359-1392. https://doi.org/10.1111/1467-6486.00384

Woodman, R. W., Sawyer, J. E., \& Griffin, R. W. (1993). Toward a Theory of Organizational Creativity. Academy of Management Review, 18, 293-321.

https://doi.org/10.5465/amr.1993.3997517 
Yeh, Y., Ko, J. R., Chang, Y. et al. (2007). Job Stress and Work Attitudes between Temporary and Permanently Employed Nurses. Stress and Health, 23, 111-120.

https://doi.org/10.1002/smi.1128 